\begin{tabular}{|c|c|c|}
\hline BENTHAM OPEN & $\begin{array}{c}\text { The Open Construction and Building } \\
\text { Technology Journal }\end{array}$ & $\begin{array}{l}\text { The Open } \\
\text { Construction \& Builting } \\
\text { Technology lournal }\end{array}$ \\
\hline CrossMark & $\begin{array}{l}\text { Content list available at: www.benthamopen.com/ТОВСТJ/ } \\
\text { DOI: } 10.2174 / 1874836801610010363\end{array}$ & ares \\
\hline
\end{tabular}

RESEARCH ARTICLE

\title{
A Study on Relationship Between the Heat Release of Later-age Concrete and the Concrete Strength Development
}

\author{
Zhenyang Zhu ${ }^{1,2, *}$, Weimin $\mathrm{Chen}^{2}$, Zhiqiang $\mathrm{Xie}^{3}$ and Guoxin Zhang ${ }^{1}$ \\ ${ }^{I}$ China Institute of Water Resources and Hydropower Research, Beijing, 100038, P.R. China \\ ${ }^{2}$ Hydrochina Huadong Engineering Corporation, Hangzhou, 310014, P.R. China \\ ${ }^{3}$ Yangtze River Scientific Research Institute, Wuhan, 430010, P.R. China
}

Received: February 15, 2016

Revised: March 11, 2016

Accepted: April 18, 2016

\begin{abstract}
The adiabatic temperature rise of early-age concrete can be precisely tested by the device. However, the insufficient accuracy of testing device can lead to inaccurate measurements of adiabatic temperature rise of later-age concrete. The purpose of this paper is to create a model to predict the hydration heat of later-age concrete. Based on the previous studies, it is known that the heat release of the concrete is accomplished with the increment of the concrete strength and concrete strength can be accurately measured. Thus, a preliminary later-age hydration heat model was established. The correction of the model was verified through experiments.
\end{abstract}

Keywords: Adiabatic temperature rise, Concrete, Heat release, Model, Strength.

\section{INTRODUCTION}

The moderate heat concrete is a kind of concrete using medium (low) hot cement with large amounts of fly ash [1]. When compared with the conventional concrete, the moderate heat concrete can generate much less hydration heat because of containing large amount of dicalcium silicate $\left(\mathrm{C}_{2} \mathrm{~S}\right)$ and fly ash. However, the process of heat release of moderate concrete is relatively slow, and there are researches indicating that fly ash hydration still exists long after concrete placement. Hence, heat release of the moderate heat concrete with fly ash is an ongoing process, contributing to cracks in the concrete dams due to the substantial interior temperature rise after pipe cooling [2 - 4]. In the previous studies, the effect of heat release of the moderate heat concrete has been studied by many researchers, and was regarded as a possible reason leading the surface cracks of high arch dams $[5,6]$.

Based on the above, it is important to get the accurate value of the heat release of the later-age concrete, but having the devices to accurately measure later-age concrete adiabatic temperature rise is limited in current practice. Methodologies and measuring devices alike intended to improve the measurement accuracy of concrete adiabatic temperature rise are in development. For example, Rlem proposed the adiabatic approximate device with limited heat release for measuring the adiabatic temperature rise of concrete, which is adjusted by a reasonable margin. Many previous researchers (Bamforth (1990), Sivasundaram (1992), Bentz (1998), Pinto (1999), et al.) have improved several aspects of the adiabatic thermometer [7 - 11] or have proposed various hydration heat models [12 - 17].

The current resolution of measuring equipment is limited to $0.005{ }^{\circ} \mathrm{C}$, which is sufficient for testing the adiabatic temperature rise of the early-age concrete, but inadequate for the later-age moderate heat concrete. How to predict or present the adiabatic temperature rise of later-age concrete has been attracted many researchers' attention. G.X. Zhang has developed an adiabatic heat combined model of high content fly-ash concrete based on laboratory tests and in situ

* Address correspondence to this author at the China Institute of Water Resources and Hydropower Research, Beijing, 100038, P.R. China; E-mail: 1219921552@qq.com 
monitoring data. Using G.X. Zhang's model, back analysis on the adiabatic heat parameters of concrete can be conducted to present the heat release of later-age concrete [5].

G.X. Zhang's model's model is mainly based on fitting and back analysis. But previous data cannot precisely represent the later data when using fitting and back analysis method. Although the adiabatic temperature rise of laterage moderate heat concrete could not be measured accurately, considering the heat release of the concrete is accomplished with the increment of the concrete strength, the relationship between concrete strength development and hydration heat release can be studied to predict the heat release of later-age concrete.

\section{RELATIONSHIP BETWEEN HEAT RELEASE OF LATER-AGE CONCRETE AND CONCRETE STRENGTH DEVELOPMENT}

\subsection{Thermal and Strength Properties of Concrete's Cementitious Materials}

Because of the insufficient accuracy of testing device, it is generally believed that the adiabatic temperature rise of later age concrete cannot be precisely measured. However, the compressive strength of later-age concrete can be measured easily. Thus, the correlated model of concrete's compressive strength and hydration heat release can be established to predict the amount and speed of hydration heat release of later-age concrete.

Concrete's cementitious materials include: dicalcium silicate $\left(\mathrm{C}_{2} \mathrm{~S}\right)$, tricalcium silicate $\left(\mathrm{C}_{3} \mathrm{~S}\right)$, tricalcium aluminate $\left(\mathrm{C}_{3} \mathrm{~A}\right)$, tetra calcium aluminoferrite $\left(\mathrm{C}_{4} \mathrm{AF}\right)$ and fly ash. The hydration heat release of tricalcium aluminate $\left(\mathrm{C}_{3} \mathrm{~A}\right)$ and tetra calcium aluminoferrite $\left(\mathrm{C}_{4} \mathrm{AF}\right)$ is more than double the amount of dicalcium silicate $\left(\mathrm{C}_{2} \mathrm{~S}\right)$, but their contribution to the compressive strength of concrete is only $10 \%$ of dicalcium silicate $\left(\mathrm{C}_{2} \mathrm{~S}\right)$. The heat release per unit mass of dicalcium silicate $\left(\mathrm{C}_{2} \mathrm{~S}\right)$ is half of tricalcium silicate $\left(\mathrm{C}_{3} \mathrm{~S}\right)$, but it can still provide the same compressive strength as tricalcium silicate $\left(\mathrm{C}_{3} \mathrm{~S}\right)$. Considering the hydration reactions of tricalcium silicate $\left(\mathrm{C}_{3} \mathrm{~S}\right)$, tricalcium aluminate $\left(\mathrm{C}_{3} \mathrm{~A}\right)$ and tetra calcium aluminoferrite $\left(\mathrm{C}_{4} \mathrm{AF}\right)$ are usually completed within 28 days, the hydration reactions of dicalcium silicate $\left(\mathrm{C}_{2} \mathrm{~S}\right)$ and fly ash continue even after 28 days. Thus, more hydration heat release is required within 28 days rather than after 28 days in order for the same amount of compressive strength to be generated.

\subsection{Thermodynamic Characteristics and Basic Assumption of the Model}

During the early stage of concreting, the cement's hydration development is closely related to the curing temperature. But in the later stage of concreting, the cement's hydration development has nothing to do with the temperature. When the age is over 28 days, the concrete hydration heat release rate is slightly correlated with temperature development.

Based on the above, the theoretical derivation of this paper is based on the following two assumptions: (1) The concrete's compressive strength is mainly contributed by the hydration products of cementitious materials (namely, the unhydrated cementitious materials will not contribute to the compressive strength); (2) For concrete over 28 days, the amount of hydrated cement can be converted into the equivalent amount of hydrated dicalcium silicate $\left(\mathrm{C}_{2} \mathrm{~S}\right)$ according to the contribution of per unit mass of cementitious material to the concrete compressive strength,.

In order to study the relationship between concrete's thermal mechanical properties, the following contents needed to be researched: (1) concrete's compressive strength and heat release contributed by the complete hydration of per unit mass of cementitious materials; (2) the relationship between the content of cementitious material and concrete's compressive strength.

\subsection{Relationship Between Cementing Material's Hydration Heat and Compressive Strength}

According to Bogue and J. C.Wang's research results (research on Portland cement hydration and its progress), the heat generated per unit mass from tricalcium silicate $\left(\mathrm{C}_{3} \mathrm{~S}\right)$ is 1.93 times that of dicalcium silicate $\left(\mathrm{C}_{2} \mathrm{~S}\right)$. The amount of hydration heat generated from tetra calcium aluminoferrite $\left(\mathrm{C}_{4} \mathrm{AF}\right)$ is 1.61 times that of dicalcium silicate $\left(\mathrm{C}_{2} \mathrm{~S}\right)$. The hydration development of tricalcium aluminate $\left(\mathrm{C}_{3} \mathrm{~A}\right)$ is 3.33 times faster than dicalcium silicate $\left(\mathrm{C}_{2} \mathrm{~S}\right)$, and the heat generated per unit mass of fly ash is 0.75 times that of dicalcium silicate $\left(C_{2} S\right)[18,19]$. It could be considered that the hydration of tricalcium aluminate $\left(\mathrm{C}_{3} \mathrm{~A}\right)$ and tetra calcium aluminoferrite $\left(\mathrm{C}_{4} \mathrm{AF}\right)$ is completed after 28 days. Set the content of tricalcium silicate $\left(C_{3} S\right)$, dicalcium silicate $\left(C_{2} S\right)$, tetra calcium aluminoferrite $\left(C_{4} A F\right)$, tricalcium aluminate $\left(\mathrm{C}_{3} \mathrm{~A}\right)$ and fly ash to $\mathrm{A}, \mathrm{B}, \mathrm{C}, \mathrm{D}$ and $\mathrm{E}$ respectively. The ratio of hydration heat generated per unit mass of cementitious materials after 28 days to the amount before 28 days is: 


$$
Q=\frac{\left(1.93 \beta_{a} A+\beta_{b} B+0.75 \beta_{e} E\right)\left(\lambda_{a} A+\lambda_{b} B+C+D+\lambda_{e} E\right)}{\left(1.93 \lambda_{a} A+\lambda_{b} B+1.61 C+3.33 D+0.75 \lambda_{e} E\right)\left(\beta_{a} A+\beta_{b} B+\beta_{e} E\right)}
$$

where $\lambda$ and $\beta$ represents the hydration ratio (i.e., ratio of hydrated amount to the total amount of a cementitious material) of various cementitious materials on or after 28 days. The hydration ratios of tricalcium silicate $\left(\mathrm{C}_{3} \mathrm{~S}\right)$, dicalcium silicate $\left(\mathrm{C}_{2} \mathrm{~S}\right)$, and tricalcium aluminate $\left(\mathrm{C}_{3} \mathrm{~A}\right)$ on the 28 th day are $\lambda_{a}, \lambda_{b}, \lambda_{e}$, respectively. The hydration ratios of tricalcium silicate $\left(\mathrm{C}_{3} \mathrm{~S}\right)$, dicalcium silicate $\left(\mathrm{C}_{2} \mathrm{~S}\right)$ and tricalcium aluminate $\left(\mathrm{C}_{3} \mathrm{~A}\right)$ after 28 days are $\beta_{a}, \beta_{b}, \beta_{e}$, respectively.

Other substances in cement such as magnesia oxide $(\mathrm{MgO})$, sulfur trioxide $\left(\mathrm{SO}_{3}\right)$ affect the heat release of concrete, and the effects of such elements usually take place in the early stage of hydration. Their effect on $Q$ can be considered according to Eq.(1).

According to European Norm EN 196-1: 187, the compressive strength of cement is commonly known as the compressive strength of concrete or mortar that is contributed by materials in the cement, such as cementitious materials. According to Bogue's research, the compressive strength contributed per unit mass of tricalcium silicate $\left(\mathrm{C}_{3} \mathrm{~S}\right)$ and dicalcium silicate $\left(\mathrm{C}_{2} \mathrm{~S}\right)$ for concrete after 28 days are the same, and the compressive strength contributed by tricalcium aluminate $\left(\mathrm{C}_{3} \mathrm{~A}\right)$ and tetra calcium aluminoferrite $\left(\mathrm{C}_{4} \mathrm{AF}\right)$ is only $10 \%$ of the compressive strength of dicalcium silicate $\left(\mathrm{C}_{2} \mathrm{~S}\right)$. The compressive strength contributed by per unit mass of fly ash is about $75 \%$ as that of dicalcium silicate $\left(\mathrm{C}_{2} \mathrm{~S}\right.$ ) (Although Fly ash contribution to the concrete compressive strength various by kind, the contribution of fly ash to the concrete compressive strength can be obtained by the ration test of concrete, which is about $75 \%$ of dicalcium silicate $\left(\mathrm{C}_{2} \mathrm{~S}\right)$ in this paper). Based on the research results of Bogue et al., the ratio of the compressive strength contributed by per unit mass of cementitious materials after $28 \mathrm{~d}$ and before $28 \mathrm{~d}$ can be deduced as:

$$
R=k \frac{\left(\beta_{a} A+\beta_{b} B+0.75 \beta_{e} E\right)\left(\lambda_{a} A+\lambda_{b} B+C+D+\lambda_{e} E\right)}{\left(\lambda_{a} A+\lambda_{b} B+0.1 C+0.1 D+0.75 \lambda_{e} E\right)\left(\beta_{a} A+\beta_{b} B+\beta_{e} E\right)}
$$

where coefficients $\mathrm{A} \sim \mathrm{E}, \lambda$ and $\beta$ are the same as Eq.(1). Considering that the compressive strength contributed per unit mass of cementitious materials in the early cementing stage is different after 28 days, a constant $k$ exists; however, its value needs to be further analyzed.

The ratio of the amount of hydration heat release required for producing a per unit of compressive strength after and before 28 days is:

$$
\xi=k \frac{Q}{R}
$$

The coefficient $\lambda$ is a constant value, and is obtained by testing. If testing results are not available, then $\lambda_{a}=0.7, \lambda_{b}=$ 0.2 and $\lambda_{e}=0.4$ are used. Also, $\lambda_{a} \varepsilon[0.6,0.8], \lambda_{b} \varepsilon[0.1,0.3]$ and $\lambda_{e} \varepsilon[0.3,0.5]$ will not greatly influence the calculation results. If retarder or an early strengthen agent is not added, then $\lambda_{a}=0.7, \lambda_{b}=0.2$ and $\lambda_{e}=0.4$ will satisfy the engineering requirements.

\subsection{Adiabatic Temperature Rise Model of Later-age Concrete}

According to Eq.(2), the concrete compressive strength on the $28^{\text {th }}$ day and the compressive strength at the age of $t$, the adiabatic temperature rise at the age of $t$ can be calculated:

$$
\theta(t)=\theta_{28}\left[\left(\frac{f_{t}}{f_{28}}-1\right) \xi+1\right] \quad t \geq 28
$$

Where $f_{t}$ and $f_{28}$ are the concrete compressive strength at the age of $t$ and $28 \mathrm{~d} . \theta_{28}$ is the adiabatic rise of concrete on $28 \mathrm{~d}$. 


\section{VERIFICATION OF THE MODEL}

\subsection{The Amount of Hydration Heat Generated Per Unit Mass of a Single Mine}

Presently, there is little discussion regarding the ratio of hydration heat generated per unit mass of each mine, but there remains a lack of understanding about the total amount of hydration heat generated per unit mass of a single mine. It is closely related to the computational method of a single mine's hydration heat. The method used for calculating a single mine's hydration heat is based on the mine's content based on the cement's chemical composition. The total amount of hydration heat generated by the cement is measured. The single mine's hydration heat is calculated using the least square method. In order to measure the cement's ultimate amount of hydration heat release, the testing process can last up to a year or more and must satisfy the heat balance principle, so as to ensure the accuracy of computational results. Considering that even the most advanced adiabatic thermometer can presently only guarantee the measurement accuracy within 28 days, it will be extremely difficult to measure the total amount of hydration heat generated for over one year accurately.

Based on the above, the amount of hydration heat generated per unit mass of a single mine takes the following values: tricalcium silicate $(\mathrm{C} 3 \mathrm{~S})=500 \mathrm{~s}$, dicalcium silicate $(\mathrm{C} 2 \mathrm{~S})=260 \mathrm{~s}$, tricalcium aluminate $(\mathrm{C} 3 \mathrm{~A})=866 \mathrm{~s}$, tetra calcium aluminoferrite $(\mathrm{C} 4 \mathrm{AF})=420 \mathrm{~s}$, sulfur trioxide $(\mathrm{SO} 3)=624 \mathrm{~s}$, free calcium oxide $(\mathrm{F}-\mathrm{CaO})=1186 \mathrm{~s}$, magnesia oxide $(\mathrm{MgO})=850 \mathrm{~s}$ and Fly-ash $=209 \mathrm{~s}$ ( $\mathrm{s}$ is a parameter, and $\mathrm{s}=1.0$ is a result tested by Bogue).

\subsection{The Relationship Between Final Hydration Rate of the Cement and the Water to Cement Ratio}

When measuring the total amount of hydration heat generated by cement, the cement hydration ratio is closely related to the water to cement ratio. Without fly ash, when the water cement ratio reaches 2.0 , cement can be hydrated by $95 \%$. But when the water cement ratio reaches 0.4 , only $70 \%$ of the cement is hydrated. The relationship between the water to cement ratio and hydration extent is as follows [20,21].

$$
\alpha_{u}=\frac{1.031 w / \mathrm{cm}}{0.194+w / \mathrm{cm}}+0.5 P_{F A}
$$

Where, $w / \mathrm{cm}$ is water-binder ratio, $P_{F A}$ is the ratio of fly ash mass to the total mass of cementitious materials, and $\alpha_{u}$ is the cement's hydration degree.

Eq. (4) is calculated under the standard curing conditions. The acceleration of the initial reaction rate at high temperatures in the early stage prevents the subsequent hydration reaction, and does not benefit the ultimate hydration of concrete. Therefore, for concrete with high hydration heat in the early stage, the ultimate hydration extent of the adiabatic temperature rise sample is obviously less than Eq.(4). The cement's hydration ratio must be calculated accurately to estimate the ultimate value of adiabatic temperature rise according to the heat release of each single mine. Hence, for the verification of Eq. (3), only the concrete with small ultimate value of adiabatic temperature rise can be adopted.

\subsection{The Result of the Experiment}

This paper adopts the mixed moderate heat concrete in the Baihetan, Kala and Yangfanggou projects to verify Eq. (3), with the verification result shown in Table 1. The verification result shows that when $\mathrm{k}=0.65$ and $\mathrm{s}=1.38$, there is a small difference between the ultimate value of adiabatic temperature rise estimated according to the heat release of each single mine and the ultimate value of adiabatic temperature rise calculated by Eq. (3). Thus, the temperature rise of later-age concrete can be obtained according to the adiabatic temperature rise and compressive strength of concrete more than 28 day age.

Table 1. Experimental data.

\begin{tabular}{|c|c|c|c|c|}
\hline Item & Material 1 & Material 2 & Material 3 & Material 4 \\
\hline Tricalcium silicate $\left(\mathrm{C}_{3} \mathrm{~S}, \mathrm{~kg}\right)$ & 39.78 & 46.02 & 48.9 & 58.48 \\
\hline Dicalcium silicate $\left(\mathrm{C}_{2} \mathrm{~S}, \mathrm{~kg}\right)$ & 32.64 & 37.76 & 40.54 & 45.74 \\
\hline Tricalcium aluminate $\left(\mathrm{C}_{3} \mathrm{~A}, \mathrm{~kg}\right)$ & 7.14 & 8.26 & 1.91 & 2.15 \\
\hline Tetra calcium aluminoferrite $\left(\mathrm{C}_{4} \mathrm{AF}, \mathrm{kg}\right)$ & 12.95 & 14.986 & 18.45 & 20.8 \\
\hline Sulfur trioxide $\left(\mathrm{SO}_{3}, \mathrm{~kg}\right)$ & 1.77 & 2.05 & 3.4 & 3.9 \\
\hline
\end{tabular}


(Table 1) contd.....

\begin{tabular}{|c|c|c|c|c|}
\hline Item & Material 1 & Material 2 & Material 3 & Material 4 \\
\hline Free calcium oxide $(\mathrm{F}-\mathrm{CaO}, \mathrm{kg})$ & 0.00 & 0 & 0.25 & 0.28 \\
\hline Magnesia oxide $(\mathrm{MgO}, \mathrm{kg})$ & 4.90 & 5.7 & 4.8 & 5.54 \\
\hline Fly-ash(kg) & 55.2 & 63.0 & 53.0 & 60.7 \\
\hline$\xi$ & 0.279 & 0.280 & 0.276 & 0.281 \\
\hline $\mathrm{w} / \mathrm{cm}$ & 0.52 & 0.45 & 0.5 & 0.45 \\
\hline $\mathrm{P}_{\mathrm{EA}}$ & 0.35 & 0.35 & 0.3 & 0.3 \\
\hline $\mathrm{f} / \mathrm{f}_{28}$ & 2.2 & 2.1 & 1.73 & 1.86 \\
\hline$\alpha_{u}$ & 0.93 & 0.91 & 0.89 & 0.89 \\
\hline $28 \mathrm{~d}$ adiabatic temperature rise $\left({ }^{\circ} \mathrm{C}\right)$ & 17.7 & 19.7 & 22 & 24 \\
\hline Ultimate value of adiabatic temperature rise estimated by heat release of single mine $(\mathrm{s}=1.38)\left({ }^{\circ} \mathrm{C}\right)$ & 23.8 & 26.7 & 25.4 & 28.6 \\
\hline Temperature rise calculated in this paper $(\mathrm{k}=0.65)\left({ }^{\circ} \mathrm{C}\right)$ & 23.6 & 25.7 & 26.4 & 29.8 \\
\hline Difference $\left({ }^{\circ} \mathrm{C}\right)$ & $0.6 \%$ & $3.9 \%$ & $4.0 \%$ & $4.1 \%$ \\
\hline
\end{tabular}

According to the verification result, the concrete mixed with fly ash and blended with moderate heat cement did not exhibit much of a difference between the amount of hydration heat release required for producing the compressive strength after 28 days. According to the result, the fly ash content and dicalcium silicate $\left(\mathrm{C}_{2} \mathrm{~S}\right)$ content of Material 1 and Material 2 are more than that of Material 3 and Material 4, and their long-term strength development and adiabatic temperature rise are both more than Material 3 and Material 4. Therefore, it can be seen that the long term strength development of concrete containing dicalcium silicate $\left(\mathrm{C}_{2} \mathrm{~S}\right)$ or mixed with fly ash exhibited a lower hydration heat in the early stage. However, the concrete containing dicalcium silicate $\left(\mathrm{C}_{2} \mathrm{~S}\right)$ or mixed with fly ash had a higher hydration heat in the later stage. The calculation of long term slow hydration heat can also form a greater temperature difference between the interior and exterior of the cement, contributing to concrete cracking on the surface or prolonging pipe cooling to a later period. Therefore, when using moderate concrete, the pipe cooling time needs to be lengthened to eliminate the adverse effect caused by long-term hydration heat.

\section{DISCUSSION}

The model of this paper was verified by the experiment data using concrete samples. However, the most directly and accurate way to verify the result and get the exact value of $\mathrm{k}$ in Eq. 3 is using the temperature rise data of mass concrete dams after pipe cooling. Due to lack of the long-term temperature rise (strength) rise data of concrete in mass dams and corresponding concrete composition, this work is hard to complete now. But the model can be improved in the further study.

\section{CONCLUSION}

During this analysis, the hydration heat model of long-stage concrete based on the compressive strength development was established and the accuracy of the model was verified by experiment. The research results of this paper also showed that the long-term strength development of concrete containing dicalcium silicate $\left(C_{2} S\right)$ or mixed with fly ash, as well as its lower hydration heat in the early stage, was beneficial for improving the pipe cooling effect and controlling temperature peaks in the early stages. However, the pipe cooling needed to be extended in order to eliminate the adverse effect caused by long-term hydration heat.

\section{ACKNOWLEDGEMENTS}

This work is supported by Natural Science Foundation of China (Nos.51409264, 51509020, and 51209219), Zhejiang provincial natural science foundation (Grant No. LQ15E090003).

\section{CONFLICTS OF INTEREST}

The authors confirm that this article content has no conflict of interest.

\section{REFERENCE}

[1] B.W. Langan, and K. Weng, "Effect of silica fume and fly ash on heat of hydration of portland cement", Cement Concr. Res., vol. 32, no. 7, pp. 1045-1051, 2002. [http://dx.doi.org/10.1016/S0008-8846(02)00742-1]

[2] Z.Y. Zhu, M.Z. Liu, S. Qiang, and J.F. Xiang, "Algorithm to simulate concrete temperature control cooling pipe boundary based on heat flux 
integration", Trans. CSAE, vol. 32, no. 9, pp. 83-89, 2016.

[3] Z.Y. Zhu, S. Qiang, and W.M. Chen, "A new method solving the temperature field of concrete around cooling pipes", Comput. Concr., vol. 11, no. 5, pp. 441-462, 2013.

[http://dx.doi.org/10.12989/cac.2013.11.5.441]

[4] Z.Y. Zhu, S. Qiang, Z.G. Zheng, and W.M. Chen, "Determination of parameters for hydration exothermic model considering concrete temperature duration by genetic algorithm", Trans. CSAE, vol. 29, no. 1, pp. 86-92, 2013.

[5] G.X. Zhang, and Y. Liu, "Hydration heat combined function model of high fly-ash concrete and its application in engineering", J. Hydroelect. Eng., vol. 31, no. 4, pp. 201-206, 2012.

[6] G.X. Zhang, and W. Zhao, "Research on thermal stress simulation and temperature controlling of super high concrete arch dams", Water Resour Hydropower Eng., vol. 39, no. 10, pp. 36-40, 2008.

[7] D.P. Bentz, V. Wallerb, and F. de Larrardb, "Prediction of adiabatic temperature rise in conventional and high-Performance concretes using a 3-D microstructural model", Cement Concr. Res., vol. 28, no. 2, pp. 285-297, 1998. [http://dx.doi.org/10.1016/S0008-8846(97)00264-0]

[8] V. Sivasundaram, and V.M. Malhotra, "Properties of concrete incorporating low quantity of cement and high volumes of ground granulated slag", ACI Mater. J., vol. 89, no. 6, pp. 554-563, 1992.

[9] R. Pinto, and K. Hover, "Superplasticizer and silica fume addition effects on heat of hydration of mortar mixtures with low watercementitious materials ratio", ACI Mater. J., vol. 96, no. 5, pp. 600-604, 1999.

[10] Y. Suzuki, N. Yokota, and S. Harada, "Applicability of adiabatic temperature rise for estimating temperature rise in concrete structures", Trans. Jpn. Concr. Inst., no. 7, pp. 49-56, 1985.

[11] A.C. Mani, "C,T, Tam and S.L. Lee,"Influence of high early temperatures on properties of PFA concrete", Cement Concr. Compos., vol. 12, no. 2, pp. 109-115, 1990 . [http://dx.doi.org/10.1016/0958-9465(90)90048-3]

[12] Z.Y. Zhu, S. Qiang, and W.M. Chen, "A model for temperature influence on concrete hydration exothermic rate (part one: theory and experiment)", J. Wuhan Univ. Tech., vol. 29, no. 3, pp. 540-545, 2014.

[http://dx.doi.org/10.1007/s11595-014-0954-z]

[13] M. Emborg, Thermal Stresses in Concrete Structures at Early Ages, Lule University of Technology: Sweden, 1989.

[14] R.O. Rasmussen, B.F. Mcculough, and D.G. Zolinger, "A foundation for high performance bounded concrete overlay design and construction guidelines", In: Proc. of $6^{\text {th }}$ Int. Conf. on Concrete Pavements, 1997, pp. 209-230.

[15] M. Cervera, J. Faria, and J. Oliver, "Numerical modeling of concrete curing regarding hydration and temperature phenomena", Comput. Struc., vol. 80, pp. 1511-1521, 2002. [http://dx.doi.org/10.1016/S0045-7949(02)00104-9]

[16] Y. Suzuki, S. Harada, and K. Maekawa, "Evaluation of adiabatic temperature rise of concrete measured with the new testing apparatus", Doboku Gakkai Rombun Hokokushu, vol. 9, pp. 109-117, 1988. [http://dx.doi.org/10.2208/jscej.1988.396_109]

[17] G. De Schutter, "Finite element simulation of thermal cracking in massive hardening concrete elements using degree of hydration based material laws", Comput. Struc., vol. 80, pp. 2035-2042, 2002. [http://dx.doi.org/10.1016/S0045-7949(02)00270-5]

[18] K.S. Anton, and J.F. Kevin, "Heat of hydration models for cementitious materials", ACI Mater. J., vol. 102, no. 1, pp. 24-33, 2005.

[19] J.C. Wang, and P.Y. Yan, "Influence of initial casting temperature and dosage of fly ash on hydration heat evolution of concrete under adiabatic condition", J. Therm. Anal. Calorim., vol. 85, no. 3, pp. 755-760, 2006.

[http://dx.doi.org/10.1007/s10973-005-7141-6]

[20] D.P. Bentz, E.J. Garboczi, C.J. Haecker, and O.M. Jensen, "Effects of cement particle size distribution on performance properties of portland cement-based materials", Cement Concr. Res., vol. 29, no. 10, pp. 1663-1671, 1999. [http://dx.doi.org/10.1016/S0008-8846(99)00163-5]

[21] R.H. Mills, "Factors influencing cessation of hydration in water-cured cement pastes", In: Proc. Symposium on the Struc. Portland Cement Paste Concr., 1996, pp. 406-424.

(C) Zhu et al. ; Licensee Bentham Open.

This is an open access article licensed under the terms of the Creative Commons Attribution-Non-Commercial 4.0 International Public License (CC BY-NC 4.0) (https://creativecommons.org/licenses/by-nc/4.0/legalcode), which permits unrestricted, non-commercial use, distribution and reproduction in any medium, provided the work is properly cited. 